\title{
Synthesis of cobalt doped mesoporous silica by using the rice husks as both silicon source and template with its catalytic oxidation of 2-methyl pyridine
}

\author{
Zhongbiao Zhai ${ }^{1,3}$, Yingchun Miao ${ }^{2 *}$, Xie Gang ${ }^{3}$, Shanshan Yang ${ }^{2}$, Jing Chen ${ }^{1}$ \\ ${ }^{1}$ Faculty of Metallurgical and Energy Engineering, Kunming University of Science and Technology, Kunming, 650093, P. R. China \\ ${ }^{2}$ College of Chemistry and Environmental Science,Qujing Nomal University, Qujing, P. R. China. \\ ${ }^{3}$ State Key Laboratory of Pressure Hydrometallurgical Technology of Associated Nonferrous Metal Resources, Kunming Metallurgical \\ Research Intitute, Kunming, 650503, P. R. China;
}

\begin{abstract}
Cobalt doped mesoporous silica $\left(\mathrm{Co}-\mathrm{SiO}_{2}\right)$ was prepared using the rice husks as both silicon source and template. Structural characterization of the catalysts was done by various techniques, such as Xray diffraction, FT-IR, $\mathrm{N}_{2}$ adsorption/desorption, and scanning electron microscopy. $\mathrm{Co}-\mathrm{SiO}_{2}$ was used as a catalyst for the oxidation of 2-methyl pyridine and exhibited high substrate conversion (94.6\%) and good product (2-pyridinecarboxylic acid) selectivity (92.4\%). It even exhibited higher selectivity than $\mathrm{Co}-\mathrm{MTiO}_{2}$, Co-MCM-41, Co-SBA-15. Fast hot catalyst filtration experiment proved that the catalyst acted as a heterogeneous one and it can be reused with almost the same activity.
\end{abstract}

\section{Introduction}

2-pyridinecarboxylic acid (2-PCA, picolinic acid) is an important intermediate for synthesis of physiologically active substances, dyes, and other synthetic chemicals[1, 2]. In general, two basic methods have been employed for the synthesis of pyridinecarboxylic acids[2]. One method is based on the hydrolysis of pyridinecarboxamides derived from pyridinecarbonitriles and the other is the oxidation of alkylpyridines /pyridineformaldehyde by air, nitric acid, selenium dioxide, etc.[2-6]. However, these methods always need critical conditions and are still expensive, polluting and risky. Although several papers deal with the heterogeneous catalytic oxidation of 2-picoline[2], the selectivity for picolinic acid was only 19 22\% with $36 \sim 74 \%$ conversion of 2-picoline. It is, therefore, of great practical interest to develop a more efficient, easily separable, reusable, and environment-friendly catalyst for the production of pyridinecarboxylic acid.

The mesoporous materials are of considerable interest in catalysis in recent years[7-10]. The general synthetic strategies for mesoporous $\mathrm{SiO}_{2}$ (such as MCM41 , SBA-15, etc.) have been developed by using surfactant as templates and tetra-ethyl orthosilicate as silicon source.

On the other hand, rice husk, a milling by-product of rice and also a major waste product of the agriculture industry. It is rich in silicon compound and has been used as silicon source to prepare silica long time ago[11-14]. Recently, silica source from rice husk ash was used as an alternative for the synthesis of mesoporous silica[15-16]. However, typical template, such as cetyltrimethylammonium bromide (CTAB) was still used as template in these synthesis processes. Whereas, the synthesis of porous silica using rice husk as templates was still very limited and in particular, the silica prepared by using rice husk as both silica source and templates has not been used in the oxidation of 2-methyl pyridine even though rice husk ash has been adopted as a catalyst support[17].

In the present work, rice husk were used as both silica source and template for the synthesis of cobalt doped mesoporous silica $\left(\mathrm{Co}-\mathrm{SiO}_{2}\right)$. It was used as a catalyst for the selectively catalytic oxidation of 2methyl pyridine (2-MP) to 2-PCA acid for the first time.

\section{EXPERIMENTAL SEACTION}

\subsection{Synthesis of $\mathrm{Co}-\mathrm{SiO}_{2}$}

$\mathrm{Co}-\mathrm{SiO}_{2}$ was synthesized with a process modified from Ref.[15-16]: Rice husks (from a farm in Honghe, Yunnan province, China.) were rinsed in $1 \mathrm{~mol} / \mathrm{L} \mathrm{HCl}$ at $363 \mathrm{~K}$ for $24 \mathrm{~h}$ to eliminate metallic impurities, and filtered out and washed with distilled water until no $\mathrm{Cl}^{-}$was detected. Then the husks were rinsed in 2propanol repeatedly until the husks were completely dehydrated. The dehydrated husks were simply dipped in a closed vessel containing a $0.1 \mathrm{~mol} / \mathrm{L}$ solution of cobalt precursor $\left(\mathrm{Co}\left(\mathrm{NO}_{3}\right)_{2} \cdot 6 \mathrm{H}_{2} \mathrm{O}\right)$ in 2-propanol. The samples were shaken in an ultrasonic bath for $1 \mathrm{~h}$ to release the air bubbles emanating from the husks and allow the solution containing cobalt ion to enter the husks more easily, and then placed quietly for $24 \mathrm{~h}$,

* Corresponding author: miaoyingchun1979@126.com 
then the husks were filtered out. The treated rice husks were dried in air at room temperature. The final rice husks were calcined at $793.15 \mathrm{~K}$ for $12 \mathrm{~h}$ in an oven in air to burn off the organics. After naturally cooling to room temperature, a black product was obtained.

\subsection{Characterizations}

Pore size distributions, BET surface areas, and pore volumes were measured by nitrogen adsorption/desorption using a NOVAtouch gas sorption analyzer (Quantachrome Corp.). Prior to the analysis, the samples were degassed at $150{ }^{\circ} \mathrm{C}$ for $1 \mathrm{~h}$.

$\mathrm{X}$-ray powder diffraction (XRD) experiments were conducted on a D/max-3B spectrometer with $\mathrm{Cu} \mathrm{K \alpha}$ radiation, and scans were made in the $2 \theta$ range $0.1-5^{\circ}$ with a scan rate $0.05^{\circ} / \mathrm{min}$ (low angle diffraction), and in the $2 \theta$ range $5-90^{\circ}$ with a scan rate of $10^{\circ} / \mathrm{min}$ (wide angle diffraction).

Scanning electron microscopy (SEM) images were taken on a TM3000 Table Microscope at an accelerating voltage of $15 \mathrm{kV}$ with the pressure in the sample chamber of 1 Torr.

FT-IR measurements were performed on a Thermo Nicolet 8700 instrument. Potassium bromide pellets containing $0.5 \%$ of the catalyst were used in FT-IR experiments and 32 scans were accumulated for each spectrum in transmission, at a spectral resolution of 4 $\mathrm{cm}^{-1}$. The spectrum of dry $\mathrm{KBr}$ was taken for background subtraction.

\subsection{Oxidation of 2-MP}

The oxidation reaction was carried out at the atmospheric pressure as follows: A certain catalyst, 2MP (AR, $0.5 \mathrm{~g}$ ) and $10 \mathrm{~mL}$ solvent (acetic acid, acetic ether, water, acetone, acetonitrile, petroleum ether, chloroform, tetrahydrofuran, formic acid, dimethyl sulphoxide) were added successively into a temperature controlled, round bottom, two-neckedflask having a reflux condenser. The aqueous $\mathrm{H}_{2} \mathrm{O}_{2}$ (30\%, approximate $3 \mathrm{~mL}$, with $2-\mathrm{MP} / \mathrm{H}_{2} \mathrm{O}_{2}$ molar ratio of 0.33 ) was added dropwise after the reaction mixture heated to the set temperature. Reaction mixture was filtered under reduced pressure after the set time. Then residue was washed with $\mathrm{CH}_{3} \mathrm{OH}$ and transferred into the $50 \mathrm{~mL}$ volumetric flask. Finally, it was analyzed by high performance liquid chromatography (Agilent 1200 series) with a packed column (Agilent ZORBAX SB C18 $150 \times 4.6 \mathrm{~mm} 5 \mu \mathrm{m})$ and an ultraviolet detector (diode array detector). The detector wavelength $\mathrm{k}=254 \mathrm{~nm}$ and temperature of column was $313.15 \mathrm{~K}$. The mobile phase was $\mathrm{CH}_{3} \mathrm{OH}$ (chromatographically pure): $\mathrm{H}_{2} \mathrm{O}=25: 75(\mathrm{~V} / \mathrm{V})$ and the flow rate was $1 \mathrm{~mL} \mathrm{~min}^{-1}$. The standard substances of 2-MP and 2-PCA were solvated in $\mathrm{CH}_{3} \mathrm{OH}$ as standard solutions.

\section{RESULTS AND DISCUSSION}

\subsection{The characterization of catalyst}

The wide-angle X-ray diffractogram patterns of $\mathrm{Co}-\mathrm{SiO}_{2}$, Co-MCM-41(CTAB) and the first recycled of $\mathrm{Co}-\mathrm{SiO}_{2}$ are shown in Figure 1.

As shown in Figure 1, it is worth noting that no distinct diffractions corresponding to any crystalline cobalt oxides are observed in the wide-angle diffractograms. This suggests the sample $\mathrm{Co}-\mathrm{SiO}_{2}$ is amorphous and also indicates that the cobalt oxides were well incorporated into the $\mathrm{SiO}_{2}$ framework, or located only the walls of mesoporous materials. From Figure 1 it is also seen that the XRD patterns of the sample $\mathrm{Co}-\mathrm{SiO}_{2}$ and the sample first recycled of Co$\mathrm{SiO}_{2}$ show similar pattern to Co-MCM-41(CTAB), which prove them have similar framework to $\mathrm{Co}$ MCM-41(CTAB)[7, 18]. This indicates that the framework of $\mathrm{Co}-\mathrm{SiO}_{2}$ has certain stability and does not change after the reaction. Moreover, there are observable lines corresponding to $\mathrm{Co}_{3} \mathrm{O}_{4}$ cubic phase in the XRD patterns of $\mathrm{Co}-\mathrm{SiO}_{2}[18]$, but the lines disappears in the XRD patterns of the first recycled of $\mathrm{Co}-\mathrm{SiO}_{2}$. The phenomenon shows that $\mathrm{Co}_{3} \mathrm{O}_{4}$ can dissolve in the reaction, and indicates that $\mathrm{Co}_{3} \mathrm{O}_{4}$ is not incorporated into the $\mathrm{SiO}_{2}$ framework, or located only the walls of mesoporous materials.

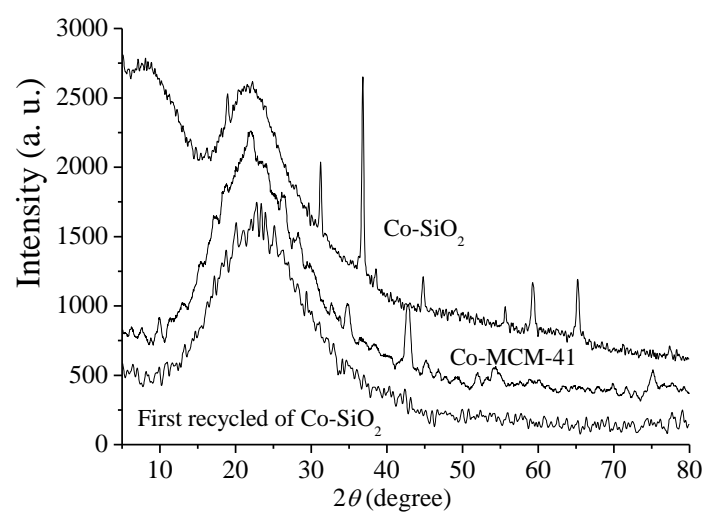

Figure 1 XRD patterns of $\mathrm{Co}-\mathrm{SiO}_{2}, \mathrm{Co}-\mathrm{MCM}-41(\mathrm{CTAB})$ and the first recycled of $\mathrm{Co}-\mathrm{SiO}_{2}$

The $\mathrm{N}_{2}$ adsorption/desorption isotherms and $\mathrm{BJH}$ pore-size distribution of $\mathrm{Co}-\mathrm{SiO}_{2}$ are shown in Figure 2 .

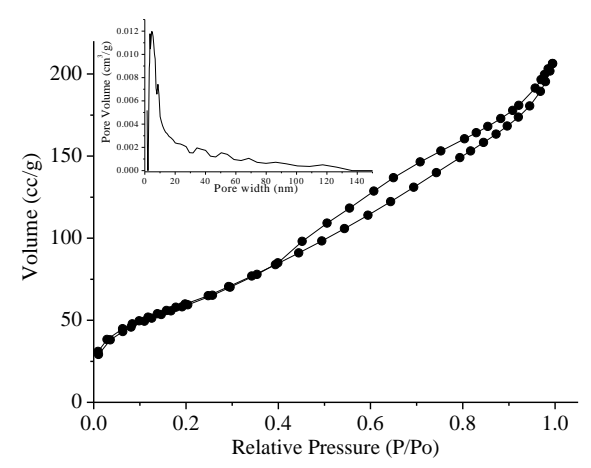

Figure $2 \mathrm{~N}_{2}$ adsorption/desorption isotherms and corresponding pore size 
The isotherm of $\mathrm{Co}-\mathrm{SiO}_{2}$ can be classified as type IV according to the IUPAC convention and indicate the mesoporous structure of prepared materials $[19,20]$. This is also supported by the average pore width (5.3 $\mathrm{nm})$, pore volume $\left(0.29 \mathrm{~cm}^{3} / \mathrm{g}\right)$, and BET surface areas $\left(221 \mathrm{~m}^{2} / \mathrm{g}\right)$, which was much lower than that of CoMCM-41. The decrease in surface areas could also be due to a coalescence process since sintering is favored by the presence of dopants[21]. The BJH pore size distribution of $\mathrm{Co}-\mathrm{SiO}_{2}$ (Inset of Figure2) also shows one primary pore size distribution in the mesopores region between $2.1 \mathrm{~nm}$ and $29 \mathrm{~nm}$ and it indicates that the catalyst has irregular pore channels.

Fig. 3 show the SEM micrographs of $\mathrm{Co}-\mathrm{SiO}_{2}(\mathrm{~b})$, the template of rice husks(a), and $\mathrm{Co}-\mathrm{SiO}_{2}$ with different magnifications (c, d).

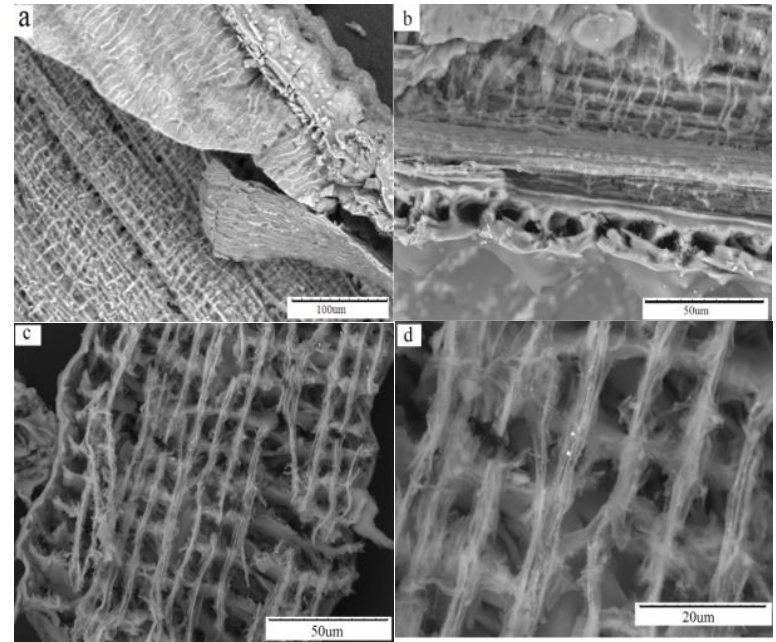

Figure 3 SEM micrographs of the template of rice husks (a), $\mathrm{Co}-\mathrm{SiO}_{2}(\mathrm{~b})$, and the positive of $\mathrm{Co}-\mathrm{SiO}_{2}$ with different magnifications (c, d).

The non-uniform lamellar structure is different from that of typical MCM-41 prepared by TEOS as silicon source and surfactant templates[7]. And Co$\mathrm{SiO}_{2}$ is also different from MCM-48 prepared by using rice husk ash as silica source and CTAB as template. As shown in Figure 3a, the morphology of rice husk has two epidermis, and between inside and outside epidermis there is a interlayer[13, 14]. Figure $3 b$ and Figure $3 \mathrm{c}$ shows that the microstructure of $\mathrm{Co}-\mathrm{SiO}_{2}$ with pore system is well-distributed and compact, which elaborately duplicated the original hierarchical structure. The internal structure of $\mathrm{Co}-\mathrm{SiO}_{2}$ whice is composed of plates arranged in a crisscross pattern like loose honeycomb and contains a lot of square holes[14]. The topography of these holes shown in Figure $3 \mathrm{~d}$ is in size of $8-20 u \mathrm{~m}$.

The FT-IR spectra of Co-SiO 2 and Co-MCM-41 were recorded between 400 and $4000 \mathrm{~cm}^{-1}$ and shown in Figure 4.

Both the samples exhibit the stretching vibration bands at around 460, 800 and $1100 \mathrm{~cm}^{-1}$ for the tetrahedral $\mathrm{SiO}_{2}$ structure[22]. Co-MCM-41 appears a very weak absorption peak at $968 \mathrm{~cm}^{-1}$, and absorption peak at $960 \mathrm{~cm}^{-1}$ disappears for $\mathrm{Co}-\mathrm{SiO}_{2}$, which implied that $\mathrm{Si}-\mathrm{OH}$ groups were consumed and transformed to $\mathrm{Si}-\mathrm{O}-\mathrm{Co}$ bonds[23,24]. Furthermore, bands between the wavelengths of 2400 and $2300 \mathrm{~cm}^{-1}$ that appear in both samples are assigned to the presence of $\mathrm{CO}_{2}$ during the sample collection. In the hydroxyl region $\left(3000-3500 \mathrm{~cm}^{-1}\right)$, the broad bands are observed at ca. $3400 \mathrm{~cm}^{-1}$ and $1640 \mathrm{~cm}^{-1}$ [25]. Especially, $\mathrm{Co}-\mathrm{SiO}_{2}$ appears two weak bands at 669 and $574 \mathrm{~cm}^{-1}$, which is different from Co-MCM-41 and related to the vibrations of $\mathrm{Co}$ (III)-O bonds in $\mathrm{Co}_{3} \mathrm{O}_{4}[26]$.

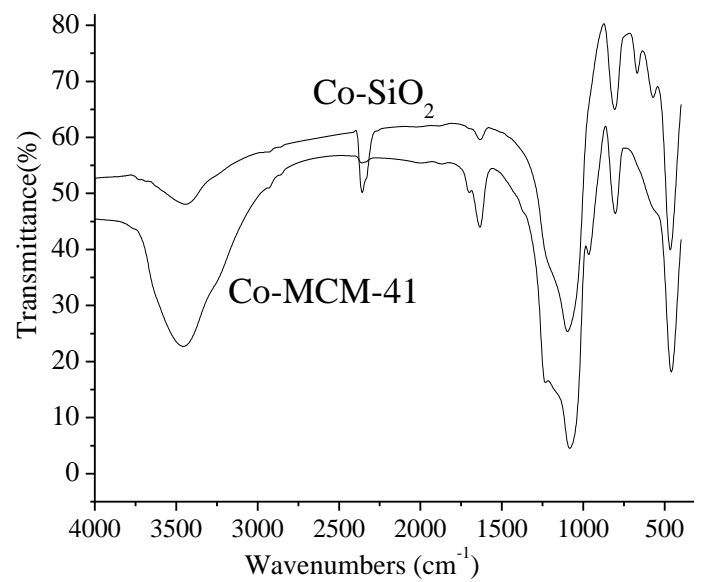

Figure 4 FT-IR spectra of Co-MCM-41 and $\mathrm{Co}-\mathrm{SiO}_{2}$

\subsection{Catalytic performance}

Using cobalt-doped $\mathrm{SiO}_{2}$ as a catalyst, it was found that 2-PCA was the major product. For comparisons, we also studied the oxidation of 2-MP over undoped $\mathrm{SiO}_{2}, \mathrm{Co}$ doped mesoporous silica (Co- $\mathrm{MTiO}_{2}$ [9], Co-MCM-41[7] and Co-SBA-15[23]). These comparisons are summarized in Table 1.

Table 1 Oxidation of 2-MP over different catalysts

\begin{tabular}{|c|c|c|c|}
\hline Catalyst & $\begin{array}{l}\text { Conversio } \\
\mathrm{n}(\mathrm{wt} \%)\end{array}$ & $\begin{array}{c}\text { Selectivity (wt\%) } \\
\text { 2-PCA }\end{array}$ & TON \\
\hline $\mathrm{SiO}_{2}$ & $<5$ & $<4$ & -- \\
\hline $\mathrm{Co}-\mathrm{SiO}_{2}$ & 94.6 & 92.4 & 313 \\
\hline Co-MCM-41 & 77.6 & 83.9 & 256 \\
\hline Co-SBA-15 & 81.5 & 82.6 & 269 \\
\hline $\mathrm{Co}^{-\mathrm{MTiO}_{2}}$ & 85.9 & 75.2 & 154 \\
\hline $\begin{array}{l}\text { First recycle } \\
\left(\mathrm{Co}-\mathrm{SiO}_{2}\right)\end{array}$ & 93.5 & 92.1 & 309 \\
\hline $\begin{array}{l}\text { Second recycle } \\
\qquad\left(\mathrm{Co}-\mathrm{SiO}_{2}\right)\end{array}$ & 92.5 & 89.3 & 305 \\
\hline
\end{tabular}

Reaction condition: Substrate/oxidant, 0.33 ; reaction time, $6 \mathrm{~h}$; reaction temperature, $363 \mathrm{~K}$; catalyst, $50 \mathrm{mg}$; solvent, acetic acid.). 
As expected, $\mathrm{SiO}_{2}$ without doped by cobalt did not show any significant activity. It is apparent that the incorporation of cobalt into silica framework significantly enhanced the activity of reaction of 2-MP. Furthermore, even doped the same cobalt, Co- $\mathrm{MTiO}_{2}$, Co-MCM-41 and Co-SBA-15 exhibited significantly lower selectivity and TON than $\mathrm{Co}-\mathrm{SiO}_{2}$. The conversion of 2-MP and selectivity of 2-PCA changed little by using $\mathrm{Co}-\mathrm{SiO}_{2}$ and the first recycled of $\mathrm{Co}-\mathrm{SiO}_{2}$ as catalyst, this may imply that the small amount of $\mathrm{Co}_{3} \mathrm{O}_{4}$ in $\mathrm{Co}-\mathrm{SiO}_{2}$ may have little influence on the oxidation of 2-MP. Although, Co-SBA-15 and Co-MCM-41 have higher surface areas $\left(690.4 \mathrm{~m}^{2} / \mathrm{g}, 1041 \mathrm{~m}^{2} / \mathrm{g}\right.$, respectively), they are much less active than $\mathrm{Co}-\mathrm{SiO}_{2}$. This may imply that pore size would play more important role since the pore size of $\mathrm{Co}_{-} \mathrm{SiO}_{2}(5.3 \mathrm{~nm})$ is bigger than those of CoSBA-15 $(3.6 \mathrm{~nm})$ and Co-MCM-41 $(2.8 \mathrm{~nm})$. In addition, porous structure diversity of $\mathrm{Co}-\mathrm{SiO}_{2}$ may be an important factor in reaction. This is because the structure-in-structure porous network could serve as transport paths for the distribution of electron onto the large surface of inner active mesoporous frameworks. Moreover, even compared with those catalysts used in the literatures [2-5], $\mathrm{Co}-\mathrm{SiO}_{2}$ with rice husk is more efficient since the yields of picolinic acid in these methods are very low $(<20 \%)$.

\subsection{Effect of solvents}

The nature of solvents was known to have a major influence on reaction kinetics and product selectivity in the oxidation of 2-MP. Therefore, the effects of solvent on catalytic activity of $\mathrm{Co}-\mathrm{SiO}_{2}$ for the oxidation of 2MP were studied first and summarized in Table 2.

Table 2 Effect of solvents on the oxidation of 2-MP

\begin{tabular}{ccc}
\hline $\begin{array}{c}\text { Solvent } \\
(10 \mathrm{~mL})\end{array}$ & Conversion of 2-MP & $\begin{array}{c}\text { Selectivity of 2- } \\
\text { MP }\end{array}$ \\
\hline Acetic acid & 96.0 & 91.1 \\
Acetic ether & 89.4 & 84.1 \\
Water & 61.5 & 67.9 \\
Acetone & 90.0 & 40.2 \\
Acetonitrile & 87.9 & 83.8 \\
Petroleum & 95.7 & 0.9 \\
ether & 88.8 & 94.4 \\
Chloroform & 64.5 & 67.3 \\
TMF & 95.8 & 12.4 \\
Formic acid & 90.2 & 77.5 \\
DMSO &
\end{tabular}

Reaction condition: Substrate/oxidant, 0.33; reaction time, 6 h; reaction temperature, $363 \mathrm{~K}$; catalyst, $50 \mathrm{mg}$; solvent, acetic acid.

It was found that $\mathrm{Co}-\mathrm{SiO}_{2}$ catalyst had the best performance in acetic acid. In other solvents the catalyst exhibited significantly lower activities. This is due to possible partial decomposition of hydrogen peroxide because it was reported that the decomposition of $\mathrm{H}_{2} \mathrm{O}_{2}$ are faster in these solvent than acetic acid. The high efficiency of $\mathrm{Co}-\mathrm{SiO}_{2}$ because of the mesoporous materials are excellent activity for catalysis. It has been reported that the framework structure of $\mathrm{Co}-\mathrm{SiO}_{2}$ can impart dual catalytic activity to the catalyst and can form labile oxygen vacancies and the relatively high mobility of bulk oxygen species[8]. In addition, a complex with peroxy acetic acid was possibly formed in the pores of $\mathrm{Co}-\mathrm{SiO}_{2}$ which is relatively more hydrophobic and stable than hydrogen peroxide. Moreover, it has been reported that acetic acid does not only act as solvent, but also serves as a good oxidizing agent[27]. In short, the synergistic affects among doped cobalt, mesoporous framework of $\mathrm{SiO}_{2}$, acetic acid, and hydrogen peroxide make $\mathrm{Co}-\mathrm{SiO}_{2}$ an effective catalyst for the oxidation of 2-MP

\subsection{Effect of reaction temperature}

The dependence of the conversion of 2-MP on the reaction temperature was investigated in the temperature range $343-383 \mathrm{~K}$ using over $\mathrm{Co}-\mathrm{SiO}_{2}$ is shown in Figure 5 .

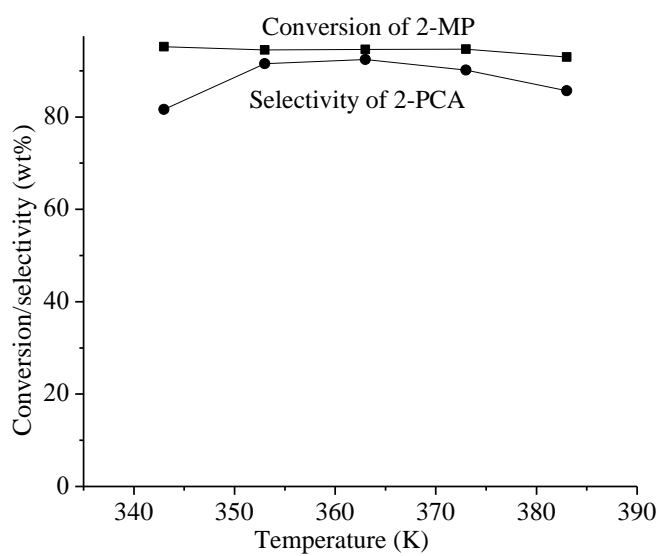

Figure 5 Effect of reaction temperature on the conversion and selectivity over $\mathrm{Co}-\mathrm{SiO}_{2}$ (Reaction condition: substrate/oxidant, 0.33; oxidant, $\mathrm{H}_{2} \mathrm{O}_{2}$; solvent, acetic acid; reaction time, $6 \mathrm{~h}$; catalyst, $50 \mathrm{mg}$.)

It is seen that the rate of 2-MP conversion decreases little with increase in reaction temperature while the selectivity of 2-PCA increased with increase in reaction temperature and passed through a maximum at $363 \mathrm{~K}$. A further increase in the reaction temperature resulted in a slight decrease in the conversion but a fast decrease in the selectivity. This would be due to a quicker decomposition of $\mathrm{H}_{2} \mathrm{O}_{2}$ at higher temperature and the over oxidation that occurred with the rising temperature when 2-MP was almost completely converted after $363 \mathrm{~K}$ Considering the effect of temperature on both conversion of 2-MP and selectivity of 2-PCA, $363 \mathrm{~K}$ was chosen as the suitable temperature for the oxidation of 2-MP.

\subsection{Effect of reaction time}

The effect of reaction time on 2-MP reaction over Co$\mathrm{SiO}_{2}$ was investigated in Figure 6. 
It is seen that the conversion of the 2-MP decreased little with time up to $12 \mathrm{~h}$ while the selectivity of 2-PCA increased with increase in reaction time and passed through a maximum at $6 \mathrm{~h}$. Beyond this time, the selectivity of 2-PCA decreased with increase in reaction time. Considering the effect of time on both conversion of 2-MP and selectivity of 2-PCA, the optimum yield of 2-PCA could be achieved at about $6 \mathrm{~h}$.

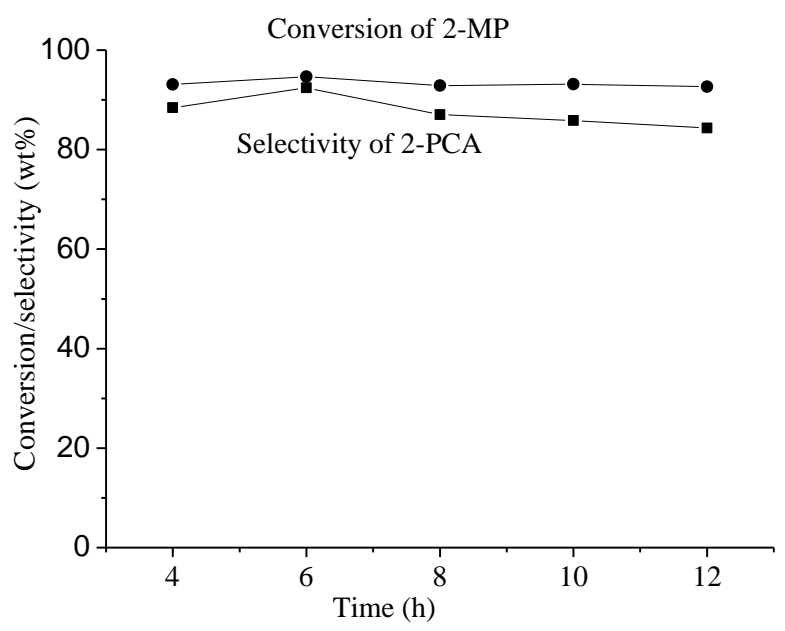

Figure 6 Effect of reaction time on the oxidation of 2-MP reaction over $\mathrm{Co}-\mathrm{SiO} 2$. (Reaction condition: substrate/oxidant, 0.33; oxidant, $\mathrm{H} 2 \mathrm{O} 2$; solvent, acetic acid; reaction temperature, $363 \mathrm{~K}$; catalyst, $50 \mathrm{mg}$.)

\subsection{Effect of catalyst concentration}

Figure 7 presents the effect of catalyst concentration on conversion of 2-MP and selectivity of 2-PCA over $\mathrm{Co}-\mathrm{SiO}_{2}$.

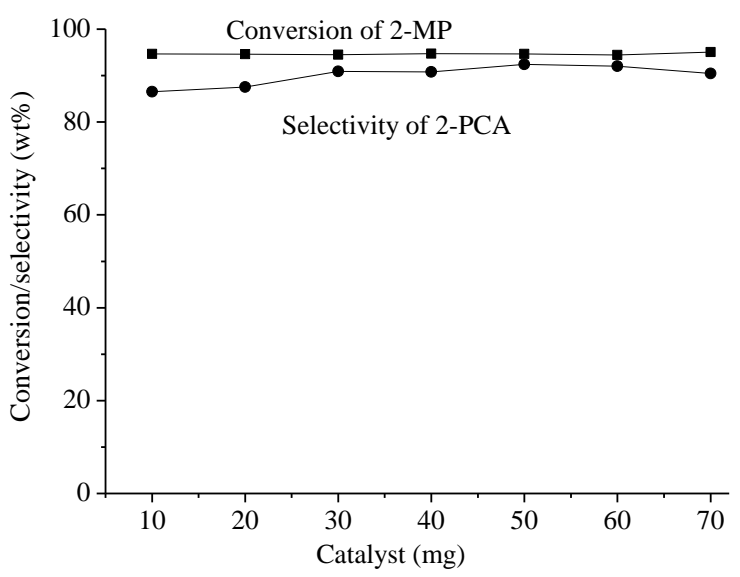

Figure7 Effect of catalyst concentration on conversion of 2$\mathrm{MP}$ and selectivity of 2-PCA over $\mathrm{Co}-\mathrm{SiO}_{2}$. (Reaction condition: substrate/oxidant, 0.33 ; oxidant, $\mathrm{H}_{2} \mathrm{O}_{2}$; solvent, acetic acid; reaction temperature, $363 \mathrm{~K}$; reaction time, 6 h.)

It is clear that the conversion of 2-MP had a slight fluctuations with the increase in the amount of catalyst, and this illustrates that the amount of catalyst changes has little effect on the conversion of 2-MP. Meanwhile the selectivity of 2-PCA slowly increased with increase in the amount of catalyst and passed through a maximum at $50 \mathrm{mg}$. Beyond this amount, the selectivity of 2-PCA decreased in the reaction mixture, and it is probable that large catalyst dosages provide excess active sites in the system to accelerate side reactions. Therefore, $50 \mathrm{mg}$ would be the optimum catalyst amount used for the selectively producing 2PCA. These results indicate that in the system catalyzed by $\mathrm{Co}-\mathrm{SiO}_{2}$ only small amount of catalyst is active in the oxidation of 2-MP at higher amount of catalyst. This could be also attributed to the possible catalytic decomposition of $\mathrm{H}_{2} \mathrm{O}_{2}$ by $\mathrm{Co}-\mathrm{SiO}_{2}$ and the competent interaction of metal oxo-species in $\mathrm{Co}-\mathrm{SiO}_{2}$ sample with 2-MP, thus inhibiting the catalytic reaction.

\subsection{The reusability and fast hot catalyst filtration experiment}

In order to prove whether the catalyst is a heterogeneous one, experiments with fast hot catalyst filtration and studying the reactivity of the filtrate had been done by a modified process as literature[27]: 50 $\mathrm{mg}$ catalyst, $500 \mathrm{mg}$ 2-MP, $20 \mathrm{~mL} \mathrm{HAc}$ and $1 \mathrm{~mL}$ $\mathrm{H}_{2} \mathrm{O}_{2}$ was stirred at the temperature of $363 \mathrm{~K}$ for one hour, then quickly filtrate the catalyst. Let the filtration to react further with by adding $2 \mathrm{~mL} \mathrm{H}_{2} \mathrm{O}_{2}$. The reaction carried out using this filtrate confirmed the absence of active metal ions as it exhibited conversion of 2-MP (16.9\%) and the selectivity of 2PCA $(13.8 \%)$. This observation was also well supported by ICP-AES analysis of the filtrates obtained from the fast hot catalyst filtration where negligible amount of leaching of active cobalt species (0.005 wt.\%) was detected. These indicated that the active component (cobalt) did not leach to the solution and the $\mathrm{Co}-\mathrm{SiO}_{2}$ did act as a heterogeneous catalyst.

Finally, to check the stability and recycling ability as well as leaching of cobalt ions from $\mathrm{Co}-\mathrm{SiO}_{2}$ under reaction conditions, recycling experiment were carried out using acetic acid as solvent. The typical recycling procedure was as follows: after the initial reaction, the catalyst was separated from mixture and washed with acetone and dried at $363 \mathrm{~K}$, followed by the activation at $793 \mathrm{~K}$ for $2 \mathrm{~h}$. The reaction was then carried out on the activated recycling catalyst. The results were also summarized in Table 1. The catalyst showed excellent reusability in the oxidation reactions. The major product was still 2-PCA, and the conversion of 2-MP and selectivity of 2-PCA changed little: the conversion from $93.5 \%$ at first use to $92.5 \%$ at second recycles, while the selectivity was from $92.1 \%$ to $89.3 \%$, respectively. Obviously, the major product was still 2-PCA. After successive cycling of the catalyst, a minor change of catalytic activity was noticed. All the observations suggest that $\mathrm{Co}-\mathrm{SiO}_{2}$ is a stable and highly effective catalyst for the oxidation of 2-MP. 


\section{Conclusions}

In conlusion, cobalt-doped $\mathrm{SiO}_{2}$ prepared by using the rice husks as both template and silicon source was an efficient catalyst for the oxidation of the 2-MP under relatively mild reaction conditions without adding any initiator. It even exhibited higher selectivity than Co$\mathrm{MTiO}_{2}$, Co-MCM-41 and Co-SBA-15. Fast hot catalyst filtration experiment proved that the catalyst acted as a heterogeneous one and it can be reused once with almost the same activity.

\section{Acknowledgements}

This work is supported by National Natural Science Foundation of China (Project NSFC-YN U1033603, 21263027, 21367024), Yunnan Applied Basic Research Project of Province (2016FB016), Science and Technology Leading Talents Training Plan (2017HA012) and Applied Basic Research Project of Qujing Normal University( JPCGPY201801). We also thank Chinese Education Ministry Key Laboratory of Resource Chemistry, Shanghai Key Laboratory of Rare Earth Functional Materials, and Program for Innovative Research Team (in Science and Technology) in University of Yunnan Province (IRTSTYN).

\section{References}

1. J. Barthelmes, W. Plieth, J. Chem. Soc., 93(1997).

2. S. Akihiro, S. Satoshi, I. Yasutaka, Org. Process Res. Dev., 4(2000).

3. N. Iwasa, T. Mayanagi, I. Ogawa, K. Sakata, N. Takezawa, Catal. Lett., 54(1998).

4. S. Järås, J. Chem. Technol. . Biot., 27(1977).

5. L. Lei, H. Song, J. Zhao, Q. Yang, Z. Chen, Anal. Methods, 11(2019).

6. M. Sudip, C. Sampatraj B, Org. Process Res., 3(1999).

7. F. Cirujano, I. Luz, M. Soukri, C. Van Goethem, I. Vankelecom, M. Lail, D. De Vos, Angew Chem. Int. Ed. Engl. 56(2017).

8. C. Ciotonea, B. Dragoi, A. Ungureanu, Catal. Sci. Technol., 7(2017).

9. Y. Leng, Y. Jiang, H. Peng, Z. Zhang, S. Dai, Catal. Sci. Technol., 9(2019) .

10. X. Ran, M. Li, K. Wang, X. Qian, J. Yang, ACS Appl. Mater. Interfaces, 11(2019).

11. H. Purwaningsih, S. Raharjo, V. Pratiwi, D. Susanti, A. Purniawan, Mater. Sci. Forum, 964(2019).

12. J. Costa, V. Sarmento, L. Romão, S. José Arnaldo, P. Luciane, C. Romão Paranhos, Pollut. Res., 26(2019).

13. Y. Shu, F. Zhang, H. Wang, RSC Advances, 9(2019).

14. N. Soltani, A. Bahrami, M. Pech-Canul, L. Gonz`alez, Chem. Eng. J., 264(2015) .

15. S. Hubadillah, M. Othman, S. Sheikh, A. Kadir, M. Jamalludin, Z. Harun, M. Aziz, M. Rahman, J. Jaafar, M. Nomura, S. Honda, Y. Iwamoto, H. Fansur, RSC Advances, 9(2019).

16. R. Bakar, R. Yahya, S. Gan, Procedia Chem., 19(2016).

17. B. Park, S. Wi, K. Lee, A. Singh, T. Yoon, Y. Kim, Biomass Bioenergy, 25(2003).

18. A. Cánepa, V. Elías, V. Vaschetti, E. Sabre, S. Casuscelli, Appl. Catal. A Gen., 545(2017).

19. R. Hou, P. Ferreira, P. Vilarinho, Micropor. Mesopor. Mat., 110(2008).

20. C. Delitala, E. Cadoni, D. Delpiano, D. Meloni, S.
Melis, I. Ferino, micropor. Mesopor. Mater., 110(2008).

21. A. Paola, G. Marci, L. Palmisano, M. Schiavello, K. Uosaki, S. Ikeda, B. Ohtani, J. Phys. Chem. B, 106(2002).

22. H. Chen, L. Liu, Nano brief reports and reviews, 14(2019).

23. C. Chen, H. Li, M. Davis, Micropor. Mater., 2(1993).

24. F. Xia, E. Ou, L. Wang, J. Wang, Dyes Pigments, 76(2008).

25. J. Yu, L. Zhang, Z. Zheng, J. Zhao, Chem. Mater., 15(2003).

26. K. Rao, H. Benqlilou-Moudden, B. Desbat, P. Vinatier, A. Levasseur, J. Solid State Chem. 165 (2002) .

27. R. Sheldon, M. Wallau, I. Arends, U. Schuchardt, Chem Res. 31 (1998). 